\title{
Developing ESP Teaching Materials Based on the Analysis of Information Engineering Majors' Needs
}

\author{
Haiyun Gu, Hua Bo, Lei Ren \\ College of Information Engineering, Shanghai Maritime University, Shanghai, China \\ Email: hygu@shmtu.edu.cn
}

How to cite this paper: Gu, H.Y., Bo, H. and Ren, L. (2019) Developing ESP Teaching Materials Based on the Analysis of Information Engineering Majors' Needs. Open Journal of Social Sciences, 7, 121-131. https://doi.org/10.4236/jss.2019.710011

Received: October 1, 2019

Accepted: October 14, 2019

Published: October 17, 2019

\begin{abstract}
Currently in China, the available ESP (English for Special Purpose) textbooks for engineering are still focused on reading, translation and grammar. Considering that Chinese undergraduates' general English levels have been improved greatly in the recent years, and many engineering students have plans to apply for graduate study or work in joint ventures in the future, their needs for ESP course have gone beyond the contents of current available textbooks. This study aims to analyze Chinese engineering undergraduates' needs on ESP course, and discuss how to develop ESP teaching materials and reform ESP teaching methods correspondingly. According to our investigation, the communication skill demanded by EMI (English as a Medium of Instruction) courses and English workplace is the most desirable professional English ability. About $85 \%$ of the students prefer using e-textbook, and $53.33 \%$ of the students vote for interactive teaching method. Moreover, cross-analysis result shows that students with different vocational plans have different priorities on professional English skills. ESP practitioners need to consider these different needs, and design diverse activities for students.
\end{abstract}

\section{Keywords}

ESP for Engineering, Students' Needs Analysis, Teaching Materials, Online Resources, Interactive Teaching

\section{Introduction}

English is recognized as the language of science and technology. So English ability is clearly very important for engineering students to understand the latest research, communicate with peers and make full use of online professional re- 
sources. Meanwhile, global economic and education create more choices for engineering students after graduation. Graduates' English communication skills in the workplace will certainly affect their future development.

In 2016, Shanghai Education Ministry revised a guidance document, the Reference Framework of English Language Teaching in Shanghai Higher Education, in which the new orientation of college English teaching was formulated as serving the needs of undergraduates' professional learning, and the proportion of specialized academic English courses was also required to be expanded [1]. ESP course, which is supposed to cultivate students' academic English abilities, should be given much more attention.

According to statistics of CNKI (China National Knowledge Infrastructure) [2], during the last decade, 49 journal articles on teaching problems of ESP for information engineering undergraduates have been published in China. Only 6 out of them were written by English teachers, comparatively, the rest authors were discipline teachers who work in College of Information Engineering, Communication Engineering, Electric and Electronic Engineering, Physics and Electronics Science, etc. So, it can be inferred that ESP courses for information engineering undergraduates are usually not taught by language teachers, but by discipline teachers in China's universities. The advantage is that discipline teachers have solid professional knowledge and advanced research skills. The disadvantage lies in the insufficiency of the discipline teachers' English communication abilities. Moreover, currently available ESP textbooks for engineering in China are still focused on reading materials, translation exercises and grammar, providing no much help for the discipline teachers to prepare ESP lectures.

This paper aims to discuss how to develop ESP teaching materials based on engineering students' needs analysis. Firstly, the primary challenges, faced by discipline teachers who teach ESP to engineering students in China, were discussed in the background section. Secondly, a questionnaire about ESP course has been designed and launched through an online survey website, and the undergraduates who major in electronic engineering and telecommunication engineering were invited to attend this investigation anonymously. Then, the results were collected and analyzed, showing that there is a serious lack of practical English communication skills cultivation in current ESP courses for engineering in China. Accordingly, in our ESP course in the fall semester of 2018, the teaching hours on translation and grammar exercises have been reduced. Instead, more video/audio materials, online professional resources and speaking practices have been adopted. Interactive teaching style is also proved to be welcomed.

\section{Background}

According to 2018 English Proficiency Index issued by the Swedish education company Education First, the English proficiency of people in Shanghai leads all cities in China for the fifth consecutive year, reaching its highest level of proficiency for the first time with a score of 57, even beating Hong Kong with a score of 56.38 [3]. But situations are not so optimistic during our practical ESP teach- 
ing process.

Chinese students do spend a lot of time learning English. The latest time to start learning English in China is the 3rd grade in the primary school, and English remains as a core subject in the entrance examination for the higher education. But the problem is that the test-oriented English education doesn't help much with the students' actual ability of using English. Besides, unlike Fulilove's investigation which revealed that engineering students in Hong Kong had no difficulties with technical vocabulary [4], in the Mainland of China, discipline courses are taught in Mandarin in most of engineering colleges. Lack of realistic English environment, information engineering students are even not familiar with the English names of the most common things in classroom, such as "projector" or "toner", not to speak of advanced technical terms. On the other hand, the engineering students' English reading ability, grammar knowledge, and listening ability have indeed been greatly improved due to the achievement of the general English teaching efforts. Once their technical vocabulary is expanded, they can do much better in academic reading and listening. But considering of the weakness of discipline teachers' and engineering students' English in actual practice, there is still a long way to go when it comes to developing engineering students' English communication skills and learning abilities under EMI environment.

Currently, all available ESP textbooks for information and electronic engineering in China are bilingual, and arranged by topics. A textbook typically consists of a dozen of units, each of which involves a major-related topic. A unit usually includes five parts of contents in this order: reading material, vocabulary, grammar, exercise, and extended reading material. The main types of exercise include multiple-choice, matching terms, translation, and filling in blanks. The appendixes usually provide the reference translation of the reading materials. Some of these ESP textbooks may contain simple Chinese introduction units about basic skills of literature retrieval, academic writing, and presentation. To summarize, current available ESP textbooks for information engineering undergraduates in China mainly focus on reading and grammar, and ignore the communication skills demanded by EMI courses and English workplace, providing no much help for the discipline teachers to prepare ESP lectures. [5] reached a similar conclusion.

Many ESP textbooks from foreign publishers are distributed globally as the content development is often obliged to compromises between commercial and pedagogical demands. Therefore, the issue of regional application and usefulness of globally published ESP textbooks has received much debate [6]. Besides, most published textbooks do not revise frequently and extensively, so whether the textbooks is up-to-date in content, approach, and methodology in order to meet latest professional areas and contexts is an issue [7]. Therefore ESP teachers often have to plan the course and provide teaching materials for it. It is rarely possible to use a ready-made published textbook without the need for supplementary material [8]. 


\section{Undergraduates' Needs Analysis}

Needs analysis is considered to be main driving factor in ESP curriculum development [9]. Moreover, students' needs are undergoing a constant change. Thus, it is critical to follow these changes and react to them [10].

\subsection{Online Survey}

In October of 2018, a students' needs survey was conducted in order to investigate their needs on ESP course. A simple questionnaire has been designed, including 6 choice questions. Participants are mainly undergraduates majoring in Electronic and Telecommunication Engineering. A total of 45 valid answers were collected.

This questionnaire was released through the most popular online survey website in China. The original survey data can be found at http://www.wjx.cn/jq/29739099.aspx.

Question 1. What is your career plan after graduation?

1) Working in state-owned companies;

2) Working in private companies;

3) Working in foreign companies;

4) Pursuing graduate studies in foreign countries;

5) Pursuing graduate studies in China;

6) Starting a business.

Participants are allowed to choose 1 - 2 options for this question, regardless of order. The result is shown in Figure 1.

Question 2. Do you think professional English ability can help you in the future work and study?
1) Definitely
2) Very likely
3) Possibly
4) Unlikely

This is a single choice question. $31.11 \%$ of the students chose (1), believing that professional English ability will definitely help them in their future career; $40 \%$ of them chose (2) very likely; the remaining $28.89 \%$ chose (3), thinking that

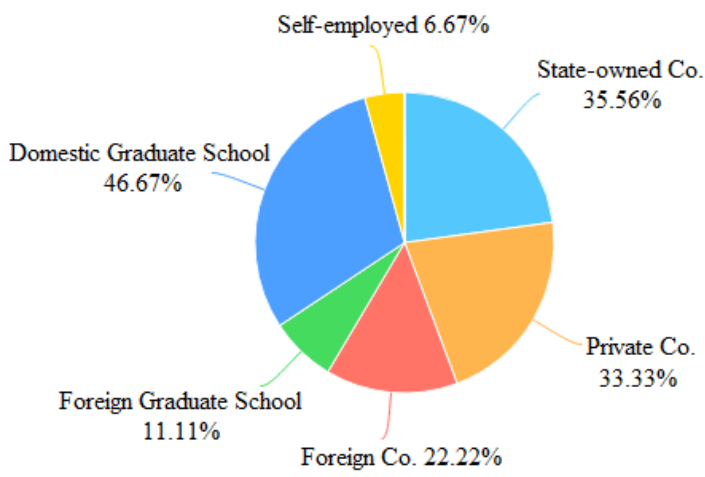

Figure 1. Distribution of participants' career plans. 
English ability might help them in some uncertain way. Not surprisingly, no student chose (4) unlikely.

Question 3. What kind of professional English skills do you most want to improve?

1) Academic English reading ability

2) Communication skills in English work environment

3) Learning ability under EMI (English as a Medium of Instruction) environment

4) Academic English writing ability

5) The ability of using English professional tools and online academic resources

This is a multiple choice question. The statistical result is shown in Figure 2. Comparing to the other techniques, the students are more inclined to improve their communication skills in English work environment.

Question 4. Which part of the current ESP textbook is most helpful to you?
1) Vocabulary
2) Reading materials
3) Grammar
4) Exercises
5) Reference translation

As mentioned above, all the available ESP textbooks for information engineering undergraduates in China are based on a single structure, including 5 basic parts (1)-(2). This question was designed to examine which part should be kept or removed. As shown in Figure 3, Vocabulary and Reading materials are the two most helpful parts considered by students. On the contrary, Exercises and Grammar parts are the least useful parts which should be reduced.

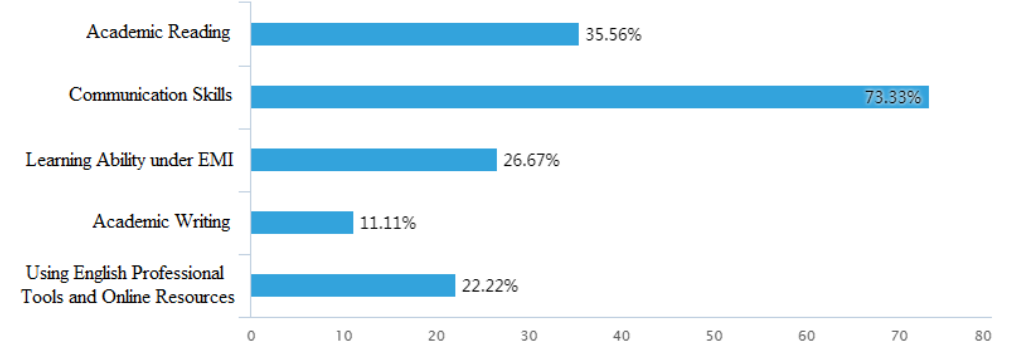

Figure 2. Survey result of the students' most desired English ability.

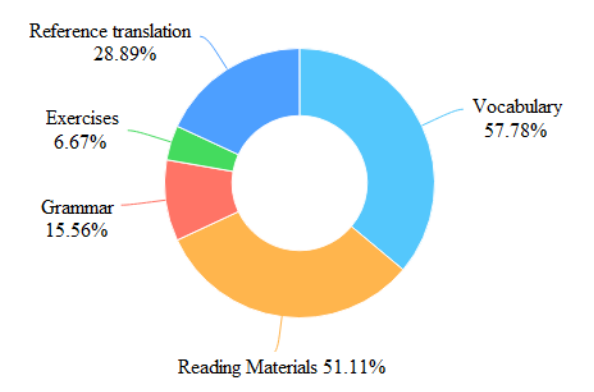

Figure 3. Students' evaluation of current ESP textbook contents. 
Question 5. If the ESP textbook is designed as an interactive E-textbook with more video/audio materials and online resources, and can be updated easily. But you need to carry your own mobile electronic equipment (smartphone, tablet, eBook Reader, etc.), do you support it?

1) Absolutely

2) It is acceptable.

3) I don't quite accept that.

The result shows that there are $15.56 \%$ of participants who didn't quite accept E-textbook. One possible reason might be that some students are just more accustomed to reading paper books.

Question 6. Which of the following teaching methods do you like most for ESP course?

1) Traditional classroom: with teachers giving lectures for most of the time, and asking a few questions; students doing homework after class

2) Interactive classroom: teaching started with teacher's lecturing to warm-up, and associated with more listening and speaking exercises, presentations, writing practices, etc.

3) Flipped classroom: requiring students to study by themselves before classes, and do more presentations and group practices in classroom

4) Online classroom: such as MOOCs or SPOCs, with flexible learning pace and time-limiting tasks

As shown in Figure 4, Chinese engineering students prefer Interactive classroom above all others.

\subsection{Analysis Results}

- Chinese engineering students are fully aware of the importance of ESP: It is no surprise that all participants believe that professional English proficiency will be of more or less assistance to their future study and work. It indicates that Learners' motivation is clearly not a problem of ESP teaching for engineering students in China.

- Communication skills in English work environment is what the engineering students most want to improve by learning ESP: The proportion of participants who most want to improve their communication skills in English working environment is surprisingly high, up to $73.33 \%$. Besides,

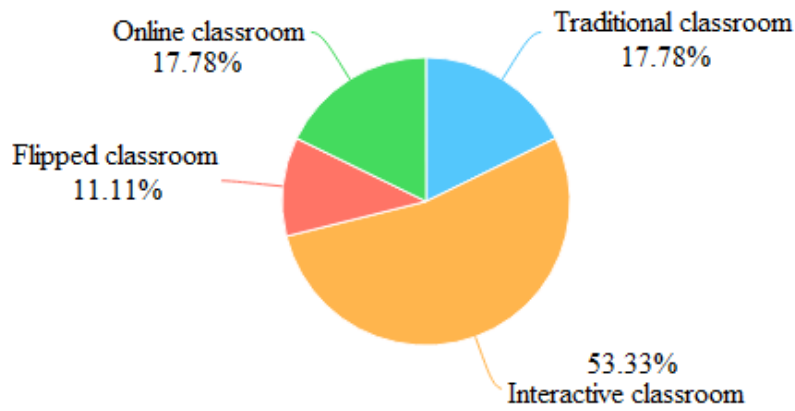

Figure 4. Students' voting on ESP teaching methods. 
because of Chinese government's promotion of EMI in engineering education, $26.67 \%$ participants hope to improve their learning ability under EMI (English as a Medium of Instruction) circumstance. This result

- The contents of ESP textbooks should be tailored to suit the engineering students' needs: Figure 5 shows the cross analysis on survey results of Question 1 (the students' future career plan) and Question 3 (the students' most desired English ability). It reveals that students with different vocational plans have different priorities on professional English skills. For example, the students who have plans to go abroad for postgraduate study are more likely to get prepared for learning under EMI. On the contrast, the students who plan to start their own business in IT industry prefer to do more practice on using English version professional software and taking full use of online English resources. ESP practitioners need to consider these different needs, and design diverse activities for students to practice in interactive classroom.

- E-textbook is a promising direction: Considering the amazing developing speed of IT technologies, an easily-updated interactive E-textbook might be more suited to ESP course for engineering, and it would be more cost effective. Up to $84.44 \%$ participants support this idea.

- Interactive classroom is the most welcoming teaching method: Chinese students are usually viewed as passive learners, especially the engineering students. But most of them agree that traditional classroom is not so good at cultivating the most deficient communication skills. Our survey found that $53.33 \%$ participants prefer interactive teaching style. According to the students' feedback after ESP class, their concern about flipped classroom mainly lies in the high demand of presentation ability, and the worries about online classroom include their deficiency of self-control and the lack of real-time guidance from teachers

\section{Developing ESP Teaching Materials}

Based on the previous students' needs analysis and our years of ESP teaching experience, in the fall semester of 2018, our ESP course for electronic and telecommunication engineering undergraduates in Shanghai Maritime University has been accordingly adjusted.

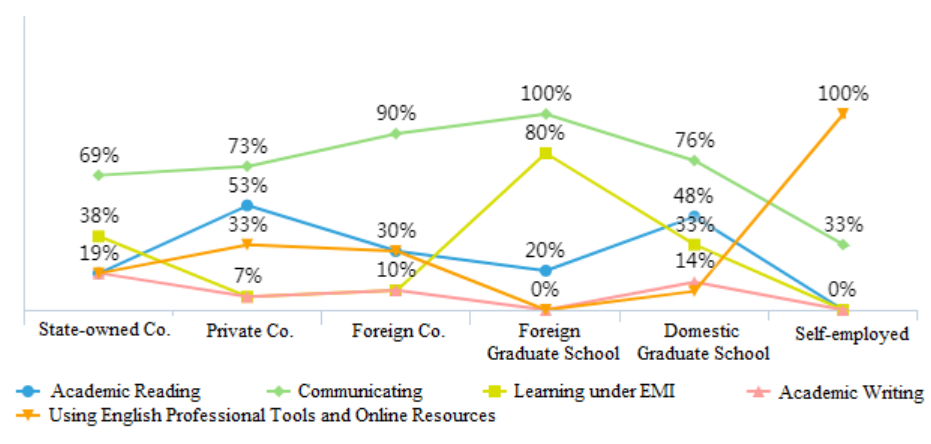

Figure 5. Cross-analysis on the results of Question 1 and Question 3. 
In this era of knowledge explosion, Internet provides us mass of resources, but also makes it difficult to find useful information. Our basic principles of choosing ESP teaching materials are as following:

- Choose materials that can represent the latest development. Keep updating materials.

- Choose materials with appropriate difficulty. Set achievable challenges which help to raise the learners' self-esteem when success is accomplished [11].

- Choose authentic materials. Authentic materials are valuable because they contain cultural aspects and show the students the real samples of language as used by native speakers [12].

- Make sure that the materials cover various researching directions to help the students' expand their vocabulary.

\subsection{Reading Materials}

ESP reading materials should include three parts: the fundamental professional knowledge, the up-to-date technologies, and the practical documents. Most of the published ESP textbooks did very well in the first part, because it is relatively easy to excerpt classical subject textbooks. To develop the second and third part of reading materials is time consuming, for there are tons of online materials nowadays. Meanwhile, ESP teachers may need to modify materials to suit the limited teaching hours, the contexts and the student' English levels. Useful resources include IT news websites, technology blogs, project descriptions, product descriptions and manuals, technical specifications, advertisements, posters, work mails, reports, researching articles, etc.

\subsection{Video/Audio Materials for Listening}

During our ESP teaching process, a strange thing was found that Chinese engineering students are very accustomed to English listening test, but unfamiliar with the real life communication. When there are no setting questions, they are more likely to miss the details. If there are several new academic terms in the listening material, it would be much more difficult for them. A compromise solution was taken to help our students improve their professional English listening skills, which includes two steps:

1) Select appropriate listening materials with related questions, standard pronunciation and slow speed to help students' learn the academic terms, such as the audio records from a global ESP textbook "Oxford English for Information Technology" (2 $2^{\text {nd }}$ edition);

2) Use authentic materials to improve students' understanding of professional listening contents, such as discipline MOOCs, TED talks on technology, and Youtube videos.

\subsection{Role Playing Conversations for Speaking}

It is not easy for discipline teachers to develop ESP speaking materials. Fortu- 
nately, there are a few academic speaking textbooks. Our approach is to set different situations and characters, provide dialogue examples, and let the students brainstorm more possible conversations. For example, the background of one situation was set as an interview scene for graduate school application. There are two characters, an electronic engineering student as the applicant and an interviewer from the graduate school. About 20 lines of an example dialogue was given as a guide, including typical questions and academic terms that could be used. The students would be asked to work in pairs to complete this dialogue.

\subsection{Work Documents and Emails for Writing}

There are two kinds of writing exercises for engineering students, academic writing and practical writing. Presently in China, an engineering student usually writes thesis in Chinese, but an English abstract is required. So the academic writing practice in our ESP course is mainly about abstract writing. The practical writing is mainly about writing work Emails and application letters to prepare the students for job market.

\subsection{The Use of Virtual Labs, Professional Software and Online Resources}

In information engineering, China's educational level, especially the experimental technology, lags behind that of other advanced countries. To help our students make full use of online experimental resources, several units were developed to introduce popular professional software, famous virtual labs, and retrieval techniques.

The original teaching hours on translations and grammar exercises have been halved. More interactive teaching technologies are applied to activate students' willing of participation, including the use of "Rain Classroom", an interactive teaching APP, and the use of screen mirroring projector. The students' feedbacks proved that our ESP teaching reform is welcomed.

\section{Conclusions}

This study presented an online survey on Chinese engineering undergraduates' needs on ESP. The answer sheets were collected and analyzed. The main problems of current ESP teaching materials for engineering root from the lack of professional English communication materials and the difficulty of updating academic reading materials in time. It is not surprising that the students support E-textbook with more video/audio materials. Besides, ESP teaching materials should include more real sources, such as IT news, work documents and emails, professional software, product descriptions, researching reports, technology speeches, employment ad, and so on.

The rapid growth of online educational resources and the fast development of information technologies in teaching bring teachers both opportunities and 
challenges. Teaching contents and methods must be adjusted accordingly to fulfill students' needs and improve the learning outcomes. In the future, our next step on ESP teaching practice is to develop an interactive ESP E-textbook for information engineering based on Adobe in Design, and provide online ESP course for Information Engineering undergraduates.

\section{Acknowledgements}

This paper is supported by EMI projects from Shanghai Municipal Education Commission, and the Textbook Construction Project of Shanghai Maritime University.

\section{Conflicts of Interest}

The authors declare no conflicts of interest regarding the publication of this paper.

\section{References}

[1] Cai, J.-G. (2017) Revision of the Reference Framework for College English Teaching in Shanghai Universities under the Background of Constructing World-Class Universities and Disciplines. https://www.sohu.com/a/166219498 528969

[2] CNKI (China National Knowledge Internet). http://www.cnki.net/

[3] Education First (2018) English Proficiency Index 2018. https://www.ef.com/ / /media/centralefcom/epi/downloads/full-reports/v8/ef-epi -2018-english.pdf

[4] Fulilove, C. (1995) Reading Technical Texts: What Type of Words Cause Problems for Engineers? M.S. thesis, Univ. Surrey, Surrey, U.K.

[5] Ke, X.-H. (2010) Primary Research on the Combination of English for Computer Course Teaching and IT Outsourcing Human Resource Pool. The 2nd International Conference on Computer and Automation Engineering, Singapore, 2010, 472-475.

[6] Huang, Y.-H. (2016) Examining the Usefulness of an ESP Textbook for Information Technology: Learner Perspectives. World Academy of Science, Engineering and Technology, International Journal of Social, Behavioral, Educational, Economic, Business and Industrial Engineering, Oct. 2016, 2798-2805.

[7] Swales, J. (1980) ESP: The Textbook Problem. The ESP Journal, 1, 11-23. https://doi.org/10.1016/0272-2380(80)90006-2

[8] Dudley-Evans, T., St John, M.J. and Saint John, M.J. (1998) Developments in English for Specific Purposes: A Multi-Disciplinary Approach. Cambridge University Press.

[9] Hossain, J. (2013) ESP Needs Analysis for Engineering Students: A Learner Centered Approach. http://presidency.edu.bd/uploads/Article003.pdf

[10] Pranckevičiūtè, V. and Zajankauskaitè, Z. (2012) Adjusting an ESP Course to Students' Needs in Tertiary Education: A Case Study. Studies about Languages, 21, 115-123. https://doi.org/10.5755/j01.sal.0.21.2465

[11] Brian, T. (2009) Principles and Procedures of Materials Development for Language Learning.

https://www.researchgate.net/profile/Vivian Cook/publication/226801437 The Go 
als of ELT/links/02bfe50ddc48b31e69000000/The-Goals-of-ELT.pdf\#page $=46$

[12] Vahid, B.Z.Z. and Ambigapathy, P. (2011) A Review on the Effectiveness of Using Authentic Materials in ESP Courses.

http://esp-world.info/Articles 31/Authenticity Effectiveness.pdf 